\title{
Editorial
}

ORL

Published online: March 3, 2006

DOI: $10.1159 / 000090484$

\section{Tinnitus: Between Research and Clinical Application}

\author{
Jean-Philippe Guyot Bert W. O'Malley, Jr.
}

This is the first controversial issue to appear in $O R L$, Journal for Oto-Rhino-Laryngology and Its Related Specialties. The concept of controversial issues was first developed for ORL Nova and was based on a trilingual format (English, German, French) with the intent of promoting exchanges between academic centers and practitioners working under different cultural and economical conditions. While this concept was successful with respect to reader enthusiasm and impact scores, its trilingual production and distribution pattern created a logistical burden that led to a collective decision to incorporate it into the ORL journal. The controversial issues will be published in English only and remain focused on encouraging discussion and critical thinking on current and controversial topics in clinical otorhinolaryngology. Recognized experts are invited to prepare a manuscript on a chosen topic which is then submitted for comments to the other invited authors. All the commentaries are published along with the invited papers. With the intent of fostering intellectual debates, we expect that some of the opinions expressed in these issues will raise additional comments among readers, which will then be published in subsequent issues of $O R L$.

This first controversial issue in $O R L$ is devoted to tinnitus, a growing complaint among our aging patient pop- ulation, and a difficult problem for most practicing otolaryngologists. On one side, the lack of scientific knowledge and data on multiple aspects of the disorder allow ample opportunity for promotion of purely money-making schemes or unfounded therapy. There are certain centers or practices that do not hesitate to advertise a high rate of success with their novel or unique therapy, however providing no data or scientific foundation to support their claims. On the other side, there are also excellent academic centers for research that have brought new insights into the diagnosis and management of tinnitus. Although patients may need a multidisciplinary and highly specialized approach to managing their disorder, the role of the primary otolaryngology practitioner remains critical as he/she will be the specialist who first evaluates the patient and establishes a direction for further diagnosis or therapy.

We hope this issue of the journal will provide a broad vision of the present research and management trends in the area of tinnitus. Our goal is not to establish a standard of care but only to present the information and controversies surrounding the topic in order to facilitate the formation of one's own opinions for counseling and directing the care of their patients.

\begin{tabular}{ll}
\hline KARGER & ○ 2006 S. Karger AG, Basel \\
Fax +4161306 1234 & 0301-1569/06/0681-0005\$23.50/0 \\
$\begin{array}{l}\text { E-Mail karger@karger.ch } \\
\text { www.karger.com }\end{array}$ & $\begin{array}{l}\text { Accessible online at: } \\
\text { www.karger.com/orl }\end{array}$
\end{tabular}

